\title{
Renal functional reserve compared in haemolytic uraemic syndrome and single kidney
}

\author{
E M Perelstein, B G Grunfeld, R B Simsolo, M I Gimenez, C A Gianantonio
}

\begin{abstract}
Creatinine clearance and microalbuminuria were measured before and after an oral protein load in 17 children with a history of haemolytic uraemic syndrome, 11 with a single kidney, and 15 controls, all of them normotensive and without evidence of renal damage, to look for indirect evidence of glomerular hyperfiltration. While creatinine clearance increased significantly after the protein load in controls, it did not change in patients with either haemolytic uraemic syndrome or a single kidney. Basal microalbuminuria was significantly higher in those with haemolytic uraemic syndrome when compared with those with a single kidney and controls. It increased significantly in all groups after a water load; this increase was significantly higher in haemolytic uraemic syndrome. After the protein load microalbuminuria returned to baseline. In conclusion, children with a history of haemolytic uraemic syndrome have an abnormal renal functional reserve like children with a single kidney. Only patients with haemolytic uraemic syndrome exhibited an increased microalbuminuria, however, suggesting that it may be the expression of a pathophysiological mechanism involved in haemolytic uraemic syndrome and not in single kidney, that could account for their different prognosis.
\end{abstract}

The haemolytic uraemic syndrome, characterised by the triad of acute renal failure, microangiopathic haemolytic anaemia and thrombocytopenia, is the main cause of acute renal failure in late infancy and early childhood. Although more than $95 \%$ of patients survive the acute phase of the disease and most of them, moreover, recover initially normal renal function, some of these patients may develop chronic renal failure in later stages of life. Haemolytic uraemic syndrome is the leading cause of chronic renal failure in childhood and adolescence in Argentina. ${ }^{1-4}$ Mechanisms responsible for the progression of renal failure in these patients remain obscure.

Glomerular hyperfiltration has been postulated as a universal mechanism implicated in the deterioration of kidney function. ${ }^{56}$ This hypothesis has stimulated the search for a method of early assessment of hyperfiltration in humans. Bosch et al introduced the concept of renal functional reserve as the capacity of the kidney to increase its level of glomerular filtration rate after an oral protein load. ${ }^{7}$ He reported that patients with overt renal disease had lost their renal functional reserve, suggesting that all their remaining nephrons were functioning at a maximal rate. He suggested that glomerular hyperfiltration might have played a pathogenetic part in the further derangement of their renal functional reserve. Further support for this contention may be drawn from experimental observations demonstrating an increase of the glomerular filtration rate in single remaining nephrons after renal ablation. ${ }^{5}$ Glomerular hyperfiltration may produce alterations in the glomerular capillary permeability, 589 leading to increased urinary albumin excretion in the microalbuminuric range. ${ }^{10}$ Microalbuminuria has thus been suggested as an early marker of hyperfiltration. ${ }^{11} 12$

The present study was undertaken to search for indirect evidences of glomerular hyperfiltration in patients with a history of haemolytic uraemic syndrome. Past morphological studies performed on kidneys of these patients during the acute phase indicated that the glomerular involvement is in fact focal and leads to a reduction in the number of their functioning nephrons. Thus results obtained in children with haemolytic uraemic syndrome were compared with those obtained in a special control group of children with a known cause of reduced renal mass such as single kidney. None of the children included in this study showed evidence of impairment in their renal function as determined by conventional methods.

\section{Patients and methods}

\section{STUDY POPULATION}

Group 1 consisted of 17 patients (nine boys, eight girls) who had a history of haemolytic uraemic syndrome. Their mean (SD) age at the time of the study was $9 \cdot 5(2 \cdot 3)$ years. The mean time of follow up from the onset of the haemolytic uraemic syndrome was $8.4(1 \cdot 7)$ years. Anuria was present during the acute episode in 11 out of 17 patients; the duration of the anuria was $8 \cdot 7(3 \cdot 2)$ days.

Group 2 consisted of 11 patients with a single kidney (seven boys, four girls). Their mean age was $10.9(3.0)$ years. All patients had undergone unilateral nephrectomy: six for reflux nephropathy, two for renal trauma, two for renal dysplasia, and one for multicystic kidney. Mean time elapsed since nephrectomy was $5 \cdot 7(1 \cdot 8)$ years.

Group 3 was the control group and it included 15 children (nine boys, six girls), mean age $10.2(2 \cdot 8)$ years, without a history of renal disease.

All children were attending the outpatient 
clinic at the Children's Hospital. They were all normotensive according to the criteria of the Task Force, ${ }^{13}$ and were not receiving any medication at the time of the study. Their creatinine clearances were within normal limits and they did not have proteinuria. Approval of the research protocol was sought and obtained from the ethical committee of the department of paediatrics. The consent of both parents and children for the present study was obtained in all cases. The study was carried out on an outpatient basis.

\section{ORAL PROTEIN LOAD}

Studies were started at 8.00 am after an overnight fast. After emptying their bladders, the children were given an oral water load of 20 $\mathrm{ml} / \mathrm{kg}$ body weight, after which two timed urine samples were collected at 30 and 60 minutes by spontaneous voiding. Blood was drawn from an intravenous butterfly needle introduced into a peripheral arm vein at the midpoint of each 30 minute period for analysis of plasma creatinine. Baseline creatinine clearance was calculated from the mean value obtained of the two 30 minute periods. The children then underwent an oral protein load (lean cooked hamburger meat) of $45 \mathrm{~g} / \mathrm{m}^{2}$ body surface area ingested during a $20-30$ minute period. After the meal was completed, three urine samples were collected at 60,120 , and 180 minutes and blood was taken for creatinine at mid-point of each period for creatinine clearance. At the end of each urine collection an equivalent volume of water was ingested by each child.

Blood pressure was measured every hour from the period before the protein load to the third hour of the period after the load with a mercury sphygmomanometer.

Plasma and urinary creatinine were measured by a standard method ${ }^{14}$ by means of an automatic analyser (Abbott VP Bichromatic Analyzer from Abbott Laboratory, Texas), and creatinine clearances were corrected for body surface and expressed per $1.73 \mathrm{~m}^{2}$.

\section{MICROALBUMINURIA}

Microalbuminuria was measured in three different urine samples: (i) in a 24 hour urine collection completed during the day before the study; (ii) in the urine collection at 60 minutes after the water load and before the protein meal; and (iii) in the urine collection at $\mathbf{1 2 0}$ minutes after the protein load. Urinary urea was measured in the last two samples. Microalbuminuria was measured by radioimmunoassay with the method of Miles $e t$ al as modified in our laboratory. ${ }^{15}$ The first antibody was purchased from Serotec (UK). Standards for iodination and standard curves were from Calbiochem Cat 126658 and 126654 respectively. Interassay variation coefficient was $15 \%$ and $13 \%$ respectively and the sensitivity was $7 \cdot 8 \mathrm{ng}$.

Urinary sodium was measured in the 24 hour collection by flame spectrophotometry.

STATISTICAL METHODS

Statistical analysis of the results was done by non-parametric methods ${ }^{1617}$ as changes in creatinine clearances after the protein load, as well as microalbuminuria, may not have a normal distribution, as stated by other authors. ${ }^{1819}$ The Wilcoxon signed rank test was used to evaluate changes in creatinine clearance after the protein load within each group. The median test was used to study the differences among the groups. Fisher's exact test on two by two contingency tables were used to determine possible associations between the response to the protein load and different clinical data. Results are expressed as mean (SE), except for microalbuminuria that is expressed antilogged with a geometric mean equivalent to the arithmetic mean of the logged data and the tolerance factor equivalent to the standard deviation of the logged data, except that the geometric mean is multiplied or divided by the tolerance factor. ${ }^{19}$ Results were considered significant when $\mathrm{p}<0.05$.

\section{Results}

After the oral protein load, normal control children significantly increased their creatinine clearance $\left(\mathrm{ml} / \mathrm{min} / 1 \cdot 73 \mathrm{~m}^{2}\right)$ when compared with baseline (131 (7)) at one hour $(153(9) ; \mathrm{p}<0.02)$, two hours (178 (10); $\mathrm{p}<0.0005)$, and three hours (192 (18); $p<0.0005)$, as shown in fig 1 . Mean percentages of increment above baseline values were $19(6) \%, 36(4) \%$, and $43(8) \%$ one, two, and three hours after the protein load respectively. The mean increment throughout the three hour period was 32 (11)\%.

In contrast, children with haemolytic uraemic syndrome failed to increase significantly their creatinine clearance above baseline $(131$ (9)) at one hour (124 (12)); two hours (125 (8)), or three hours $\left(134(10) \mathrm{ml} / \mathrm{min} / 1 \cdot 73 \mathrm{~m}^{2}\right)$ after the protein load. Mean percentages of increment above baseline were $-1(6) \%, 2(7) \%$, and $4(6) \%$ at one, two, and three hours after the oral protein load respectively. Like the patients with haemolytic uraemic syndrome, patients with a single kidney also failed to increase significantly their creatinine clearance after the protein load. Values recorded were: baseline 138 (17); one hour 116 (17); two hours 136 (14), and three hours $136(9) \mathrm{ml} / \mathrm{min} / 1 \cdot 73 \mathrm{~m}^{2}$. Mean increments above baseline were $-12(10) \%, 3(11) \%$, and $-3(9) \%$ at one, two, and three hours after the protein load.

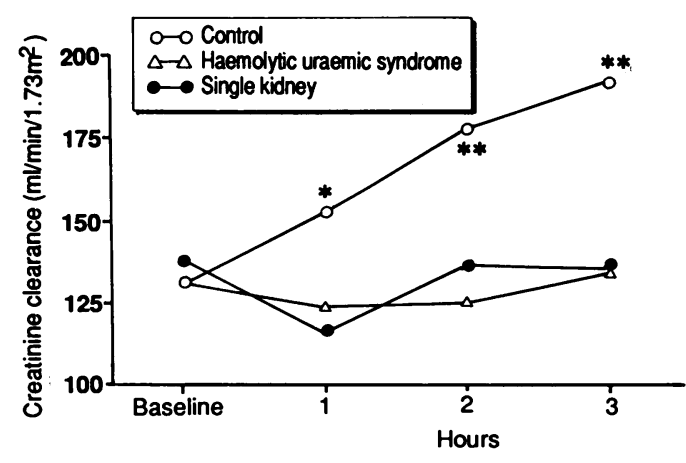

Figure 1 Creatinine clearances after an oral protein load. ${ }^{*} p<0.02,{ }^{*} p<0.0005$ compared with respective baseline. 
Both patients with haemolytic uraemic syndrome and a single kidney showed a great variation in the values of the individual responses of the creatinine clearance to the protein load. Thus a more discriminative analysis of the results obtained showed that six out of 17 (35\%) patients with haemolytic uraemic syndrome and two of $11(18 \%)$ patients with a single kidney were in fact able to increase their creatinine clearance to values within $2 \mathrm{SD}$ of the responses shown by normal controls.

No significant changes in blood pressure were recorded throughout the study.

Plasma creatinine was $0.58(0.03) \mathrm{mg} \%$ at baseline and $0.60(0.03) \mathrm{mg} \%$ three hours after the protein load; this was not significant.

The lack of creatinine clearance response to the protein load in patients with haemolytic uraemic syndrome was significantly related $(p<0.05)$ to the presence of anuria during the acute phase of the disease. No additional significant associations were found when other clinical variables, such as sex, age at onset, prodromes of the acute phase, hypertension during the acute phase, or time elapsed between the acute phase and time of study were analysed.

Baseline urinary albumin excretion values before water load were significantly higher in the group with haemolytic uraemic syndrome $(p<0.05)$ when compared with either of the two other groups (haemolytic uraemic syndrome: $11.7 \mu \mathrm{g} / \mathrm{min}$, tolerance factor 3.4 ; single kidney: $2.0 \mu \mathrm{g} / \mathrm{min}$, tolerance factor 1.6 ; and controls: $2.9 \mu \mathrm{g} / \mathrm{min}$, tolerance factor 1.5 ). Although mean urinary albumin excretion increase one hour after the water load was significant in each group compared with its respective baseline, the increase was significantly higher in the group with haemolytic uraemic syndrome (haemolytic uraemic syndrome: $33.5 \mu \mathrm{g} / \mathrm{min}$, tolerance factor $4.0, \mathrm{p}<0.005$; single kidney: $4.6 \mu \mathrm{g} / \mathrm{min}$, tolerance factor $1.5, \mathrm{p}<0.05$; and controls: 8.8 $\mu \mathrm{g} / \mathrm{min}$, tolerance factor $1.9, \mathrm{p}<0.05)$. Two hours after the protein load urinary albumin excretion had returned to baseline values in all the groups (fig 2). Although mean urinary albumin excretion one hour after the water load was higher in the children with haemolytic uraemic syndrome who showed no increase in their creatinine clearance after the protein load ('nonresponders'), when compared with children with haemolytic uraemic syndrome who did

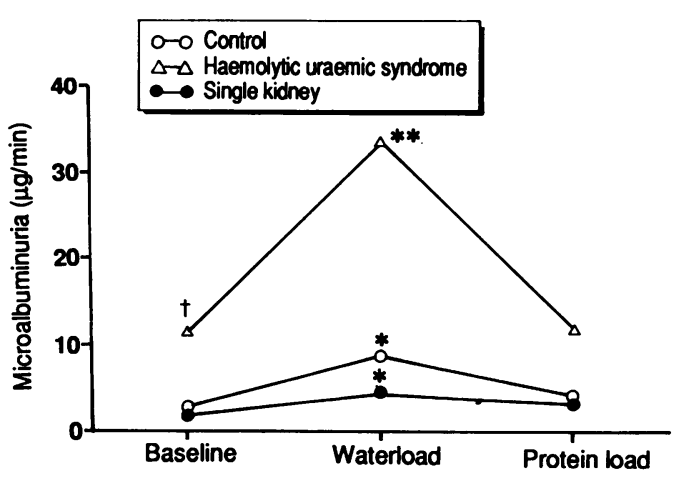

Figure 2 Microalbuminuria after an oral water load and an oral protein load. ${ }^{*} p<0.05,{ }^{* *} p<0.005$ compared with respective baseline; $t p<0.03$ compared with control. increase their creatinine clearance ('responders'), this difference was not significant (50 $\mu \mathrm{g} / \mathrm{min}$, tolerance factor 4 and $15.8 \mu \mathrm{g} / \mathrm{min}$, tolerance factor $3 \cdot 1$ respectively).

\section{Discussion}

Our results indicate that the creatinine clearance response to an oral protein load is below 2 SD of those of normal controls in most patients with either a history of haemolytic uraemic syndrome or with a single kidney. This suggests that both groups of patients present an abnormal renal functional reserve despite having shown normal renal function by standard diagnostic procedures. If a reduced renal functional reserve indicates in fact a loss of intact nephrons ${ }^{7}$ it may then be assumed that the past episode of haemolytic uraemic syndrome could have left these patients with a reduced number of functioning nephrons which, undisclosed by conventional methods of renal function assessment, led to a decreased renal functional reserve similar to the one present in children with a single kidney. Our finding of a significant association between the presence of anuria during the acute phase of haemolytic uraemic syndrome (suggesting severe renal involvement) and the lack of renal functional reserve adds further evidence to this assumption.

We used the endogenous creatinine clearance as an estimate of the glomerular filtration rate based on other authors' findings that creatinine clearance and inulin clearance render similar results in this test. ${ }^{720}$ Although it has long been known that both clearances may be discordant because of tubular secretion of creatinine, this discrepancy becomes important only when the glomerular filtration rate is decreased. Differences between both clearances have been reported to be less than $10 \%$ in subjects with normal renal function. ${ }^{21} 22$ Finally, the purpose of using an oral protein load was to observe the dynamic behaviour of the creatinine clearance rather than study its absolute value.

Some authors have reported that cooked red meat may increase the plasma creatinine, which may in turn influence the tubular secretion of creatinine. ${ }^{23}$ If this were the case in our study we should have found 'spurious' increases in the creatinine clearance instead of a lack of response. Moreover, no changes in plasma creatinine were found after the protein load used in our experimental design.

Although both patients with haemolytic uraemic syndrome and a single kidney presented abnormalities in their renal functional reserve, only children with a history of haemolytic uraemic syndrome showed significantly increased baseline and water stimulated microalbuminuria when compared with normal controls. Microalbuminuria has previously been shown to increase after a water load ${ }^{24}$ and after a simultaneous water and protein load. ${ }^{25}$ The design of the present study allowed us to confirm that the water load, rather than the protein load, was responsible for the increase in microalbuminuria.

To our knowledge, no data on renal functional reserve or microalbuminuria in children 
with a history of haemolytic uraemic syndrome or a single kidney have previously been published. In adult single kidney patients, the published information is controversial, as some authors reported a diminished renal functional reserve, ${ }^{7} 182026$ whereas others found it to be normal. ${ }^{27}$ Increased microalbuminuria in adults with a single kidney has recently been reported. ${ }^{24}$ Normal microalbuminuria in our children with a single kidney could be explained by either a shorter time elapsed since surgery or differences in the original disease which led to nephrectomy.

In conclusion, we have found that children with a history of haemolytic uraemic syndrome with a present normal renal function (as determined by standard diagnostic procedures) have an abnormal renal functional reserve, similar to a control group of children with a single kidney and normal renal function. The fact that only patients with haemolytic uraemic syndrome exhibited a raised microalbuminuria would suggest that, although both entities have a reduced number of functioning nephrons, additional pathophysiological mechanisms are operating in the patients with haemolytic uraemic syndrome, which may account for the different prognosis.

1 Gianantonio CA, Vitacco M, Mendilaharzu F, Rutty A, Mendilaharzu J. The hemolytic-uremic syndrome. f Pediatr 1964;64:478-9.

2 Gianantonio CA, Vitacco M, Mendilaharzu F, Gallo GE. The hemolytic-uremic syndrome. Renal status of 76 patients at long-term follow-up. $\mathcal{J}$ Pediatr 1968;72:757-65.

3 Gianantonio CA, Vitacco M, Mendilaharzu F, Gallo GE, Sojo ET. The hemolytic-uremic syndrome. Nephron 1973;11: ET. The

4 Gianantonio CA. The hemolytic-uremic syndrome. In: Edelmann CM, ed. Pediatric kidney disease. Boston: Little, Brown and Co, 1978:724-36.

5 Hostetter TH, Olson JL, Rennke HG, Venkachatalam MA Brenner BM. Hyperfiltration in remnant nephrons: potentially adverse response to renal ablation. Am $\mathcal{f}$ Physio 1981;241:F85-93.

6 Brenner MB, Meyer TW, Hostetter TH. Dietary protein intake and the progressive nature of kidney disease: the role of hemodynamically mediated glomerular injury in the pathogenesis of progressive glomerular sclerosis in aging renal ablation and intrinsic renal disease. $N \mathrm{Engl} \mathrm{f} \mathrm{Med}$ 1982;307:652-9.
7 Bosch JP, Sacaggi A, Lauer A, Ronco C, Belledonne M, Glabman $S$. Renal functional reserve in humans. Effect of protein intake on glomerular filtration rate. Am $\mathcal{F} \mathrm{Med}$ 1983;75:943-50.

8 Purkenson ML, Hoffsten PE, Klahr S. Pathogenesis of the glomerulopathy associated with renal infarction in rats. Kidney Int 1976;9:407-17.

9 Olson JL, Hostetter TH, Rennke HG, Brenner BM, Venkatachalam MA. Altered glomerular permselectivity and progressive sclerosis following extreme ablation of renal mass. Kidney Int 1982;22:112-26.

$10 \mathrm{Kanwar}$ YS. Biology of disease. Biophysiology of glomerular filtration and proteinuria. Lab Invest 1984;51:7-21.

11 Viberti GC, Hill RD, Jarrett RJ, Argyropoulos A Mahmud R, Keen $\mathbf{H}$. Microalbuminuria as a predictor of clinical nephropathy in insulin-dependent diabetes mellitus. Lancet 1982;i:1430-2

12 Mogensen CE. Microalbuminuria predicts clinical proteinuria and early mortality in maturity-onset diabetes. $N$ Engl f Med 1984;310:356-60.

13 Report of the Second Task Force on Blood Pressure Control in Children. Pediatrics 1987;79:1-25.

14 Owen JA, Iggo B, Scandrett PJ, Stewart CP. The determination of creatinine in plasma and in urine: a critical examination. I Biol Chem 1954;58:426-37.

15 Miles DW, Mogensen CE, Gundersen HJG. Radioimmunoassay for urinary albumin using a single antibody. Scand $\mathcal{f}$ Clin Lab Invest 1970;26:5-11.

16 Snedecor GW, Cochran WG. Statistical methods. 7th Ed. Ames, Iowa: The Iowa State University Press, 1980: Ames,

17 Daniel WW. Biostatistics. A foundation for analysis in the health sciences. 4th Ed. New York: Wiley, 1987:583-636.

18 Rodriguez-Iturbe B, Herrera J, Garcia R. Response to acute protein load in kidney donors and in apparently normal postacute glomerulophritis patients: evidence for glomerular hyperfiltration. Lancet $1985 ;$;i: $461-4$

19 Davies AG, Postlethwaite RJ, Price DA, Burn JL, Houlton CA, Fielding BA. Urinary albumin excretion in school children. Arch Dis Child 1984;59:625-30.

20 Bosch JP, Lauer A, Glabman S. Short-term protein loading in assessment of patients with renal disease. Am $\mathcal{f} M e d$ 1984;77:873-9.

21 Bauer JH, Brooks CS, Burch RN. Clinical appraisal of creatinine clearance as measurement of glomerular filtration rate. Am $\mathcal{F}$ Kidney Dis 1982;2:337-46.

22 Shemesh O, Golbetz H, Kriss JP, Myers BD. Limitations of creatinine as a filtration marker of glomerulopathic patients. Kidney Int 1985;28:830-8.

23 Jacobsen FK, Christensen C, Mogensen C, Andreasen F Heilskov N. Pronounced increase in serum creatinine Heilskov N. Pronounced increase in serum creatinine

24 Amore A, Coppo R, Roccatello D, et al. Single kidney function: effect of acute protein and water loading on microalbuminuria. Am $\mathcal{F}$ Med 1987;84:711-7.

25 Viberti GC, Mogensen CE, Keen H, Jacobsen FK, Jarret RJ, Christensen CK. Urinary excretion of albumin in normal man: the effect of water loading. Scand $\mathcal{F}$ Clin Lab Invest 1982;42:147-51.

26 Wheeler DC, Cosgriff PS, Bennett SE, Walls J. Measuremen of renal functional reserve of the single kidney in man. Clin Nephrol 1987;28:87-92.

27 Rugiu C, Oldrizzi L, Maschio G. Effects of an oral protein load on glomerular filtration rate in patients with solitary kidneys. Kidney Int 1987;32(suppl 2):529-31. 